\title{
Unemployment Insurance, Unemployment Durations and Re-employment Wages
}

\author{
Brian McCall \\ University of Minnesota \\ Address: 3-251 Carlson School of Management \\ $32119^{\text {th }}$ Avenue South, Minneapolis, MN 55455 \\ Email: bmccall@csom.umn.edu
}

Wei Chi

Tsinghua University, Beijing, China

Address: E-51 School of Economics and Management, Tsinghua University, Beijing, China, 100084

Email: chiw@em.tsinghua.edu.cn 


\title{
Unemployment Insurance, Unemployment Durations and Re-employment Wages
}

\begin{abstract}
We develop an empirical model to estimate the impact of UI on unemployment duration and reemployment wages. The model estimates the UI receipt, unemployment duration and re-employment wage equations simultaneously and incorporates unobserved heterogeneity variables in each equation and allows them to be correlated. The NLSY79 data is used to estimate the model. Some results are found support of the positive effect of UI on re-employment wages.
\end{abstract}




\section{Introduction}

The disincentive effect of unemployment insurance (UI) benefits has been discussed extensively in the unemployment and UI literature. A substantial amount of empirical evidence has been found in support of the hypotheses that extending benefit durations or increasing benefit levels decrease the reemployment hazards and increase the joblessness durations of the unemployed. ${ }^{1}$ However, UI receipt may have a positive effect on post-displacement wages.

The difficulty in measuring the effect of UI is because the receipt of UI, the benefit level and duration are potentially endogenous. Individuals who expect a long unemployment spell and large earning drop may be more likely to claim benefits, UI recipients may be found to have relatively lower post-displacement wages than non-recipients. Little research has been done that estimates UI receipt, unemployment duration, and post-displacement earnings simultaneously while accounting for selectivity due to UI receipt and unobserved heterogeneity in UI receipt, unemployment duration, and subsequent wage. ${ }^{2}$

\section{Empirical Model}

We develop a multi-episode, random-effects model of the duration of unemployment and re-employment wage following a job loss that allows the unobservable determinants of UI receipt to be correlated with the unobservable determinants of the unemployment duration and re-employment wage

\footnotetext{
1 These studies include the U.S. studies by Meyer (1990), Fallick (1991), and Card and Levine (2000) the Canadian study by Ham and Rea (1987).

2 Devine and Kiefer (1991) summarize earlier findings on the effect of UI on post-displacement wages. Recent studies of UI and post-displacement wages include Addison and Blackburn (2000).
} 
The model uses a discrete-time hazard model for unemployment durations (see Meyer, 1990). Let $D_{s}$ be the time until the person becomes reemployed after the $\mathrm{s}^{\text {th }}$ job loss and let $C_{s}$ be a censoring variable which equals one if the spell is incomplete. Define $K_{s}=\min \left\{D_{s}, C_{s}\right\}$.

The discrete hazard of re-employment at k weeks of unemployment is

$$
P\left(D_{s}=k \mid K>k-1, \mathbf{x}_{s k}, \mathbf{y}_{s k}, \xi^{d}\right)=1-\exp \left(-\xi^{d} \exp \left(\mathbf{x}_{s k}^{\prime} \boldsymbol{\beta}^{d}+\mathbf{y}_{s k}^{\prime} \boldsymbol{\delta}^{d}\right) \lambda_{k}\right)
$$

where $\mathbf{x}_{\mathbf{s k}}$ is a vector of exogenous (possibly-time varying) variables, $\mathbf{y}_{\mathrm{s}}$ is a vector of possibly endogenous variables and $\lambda_{k}$ are the baseline hazard parameters.

Here the endogenous variables in the duration equation are all functions of one endogenous variable, UI receipt, which we denote by $\mathrm{u}_{s}$ and model by

$$
\mathrm{P}\left(\mathrm{u}_{\mathrm{s}}=1 \mid \mathbf{z}, \xi^{u}\right)=1-\exp \left[-\xi^{u} \exp \left(\mathbf{z}_{s}^{\prime} \boldsymbol{\beta}^{u}\right)\right]
$$

where $\mathbf{z}$ is a vector of exogenous variables (which may include some variables from $\mathbf{x}$ ) and $\xi^{u}$ is an unmeasured variable that is assumed to be independent of $\mathbf{z}$ and $\mathbf{x}$. If $\xi^{d}$ and $\xi^{u}$ are correlated then not explicitly modeling $\mathrm{u}_{\mathrm{s}}$ may result in biased estimates of the parameters in (1).

Finally, we assume that the re-employment wage after the $\mathrm{s}^{\text {th }}$ job loss, $\mathrm{w}_{\mathrm{s}}$, is log-normally distributed:

$$
f\left(\mathrm{w}_{s} \mid \mathbf{x}_{s}, \mathbf{y}_{s}, \xi^{w}\right)=\frac{1}{w_{s}} \phi\left(\frac{\ln \mathrm{w}_{s}-\mathbf{x}_{s} \beta^{w}-\mathbf{y}_{s} \delta^{w}-\xi^{w}}{\sigma^{w}}\right)
$$

where, $\phi$ is the p.d.f. of a standard normal random variable, $\sigma^{w}$ is its standard deviation, $\mathbf{x}_{s}$ is a vector of exogenous variables and $\mathbf{y}_{s}$ is a vector of endogenous variables both measured at the start of the job measured at the start. Here the endogenous variables in the wage equation are various functions of UI receipt and the duration of unemployment. While the conditional distribution (on $\xi^{w}$ ) of $\mathrm{w}$ is 
potential restrictive, the unconditional distribution being a mixture of log normally distributed random variables is more flexible.

Under (1) - (3), the likelihood function for the $\mathrm{i}^{\text {th }}$ individual is then

$$
\begin{aligned}
& L_{i}=\int \prod_{s=1}^{S_{i}}\left\{1-\exp \left[-\xi^{u} \exp \left(\mathbf{z}_{s i}^{\prime} \boldsymbol{\beta}^{u}\right)\right]\right\}^{\mathrm{u}_{i}}\left\{\exp \left[-\xi^{u} \exp \left(\mathbf{z}_{s i}^{\prime} \boldsymbol{\beta}^{u}\right)\right]\right\}^{1-u_{i}}\left[\exp \left(-\xi^{d} \sum_{m=1}^{K_{s i}-1} \exp \left(\mathbf{x}_{s k i}^{\prime} \boldsymbol{\beta}^{d}+\mathbf{y}_{s k i}^{\prime} \boldsymbol{\delta}^{d}\right) \lambda_{m}\right]\right. \\
& \left\{\left[1-\exp \left(-\xi^{d} \exp \left(\mathbf{x}_{s i}^{\prime} \boldsymbol{\beta}^{d}+\mathbf{y}_{s k i}^{\prime} \boldsymbol{\delta}^{d}\right)\right) \lambda_{K_{s i}}\right] \frac{1}{w_{i s}} \phi\left(\frac{\ln \mathrm{w}_{i s}-\mathbf{x}_{s k i}^{\prime} \boldsymbol{\beta}^{w}-\mathbf{y}_{s i}^{\prime} \boldsymbol{\delta}^{w}-\xi^{w}}{\sigma^{w}}\right) d G\left(\xi^{u}, \xi^{d}, \xi^{w}\right)\right\}^{c_{s i}}
\end{aligned}
$$

where $\mathrm{G}\left(\xi^{\mathrm{u}}, \xi^{d}, \xi^{w}\right)$ is the distribution of the unobserved heterogeneity parameters and $\mathrm{c}_{\mathrm{si}}$ is a censoring variable that equals 1 if the $\mathrm{i}^{\text {th }}$ individual's unemployment spell is complete. We assume that the unobserved heterogeneity distribution has a mass-point specification in which there are $\mathrm{R}$ types of individuals in the population with type $m$ having the unique pair $\left(\xi_{m}^{u}, \xi_{m}^{d}, \xi_{m}^{w}\right)$ of “location” points and composing the fraction $\mathrm{p}_{\mathrm{r}}$ of the population, $\mathrm{r}=1, \ldots, \mathrm{R}$, where $\sum_{r=1}^{R} p_{r}=1$. In this case the likelihood for the $\mathrm{i}^{\text {th }}$ individual becomes:

$$
\begin{aligned}
& L_{i}=\sum_{r=1}^{R} p_{r} \prod_{s=1}^{S_{i}}\left\{1-\exp \left[-\xi_{r}^{u} \exp \left(\mathbf{z}_{s i}^{\prime} \boldsymbol{\beta}^{u}\right)\right]\right\}^{\mathrm{u}_{i}}\left\{\exp \left[-\xi_{r}^{u} \exp \left(\mathbf{z}_{s i}^{\prime} \boldsymbol{\beta}^{u}\right)\right]\right\}^{1-\mathrm{u}_{i}}\left[\exp \left(-\xi_{r}^{d} \sum_{m=1}^{k_{s i}-1} \exp \left(\mathbf{x}_{s i}^{\prime} \boldsymbol{\beta}^{d}+\mathbf{y}_{s i}^{\prime} \boldsymbol{\delta}^{d}\right) \lambda_{m}\right]\right. \\
& \left\{\left[1-\exp \left(-\xi_{r}^{d} \exp \left(\mathbf{x}_{s i}^{\prime} \boldsymbol{\beta}^{d}+\mathbf{y}_{s i}^{\prime} \boldsymbol{\delta}^{d}\right)\right) \lambda_{k_{s i}}\right] \frac{1}{w_{i s}} \phi\left(\frac{\ln w_{i s}-\mathbf{x}_{i s}^{\prime} \boldsymbol{\beta}^{w}-\mathbf{y}_{s i}^{\prime} \boldsymbol{i}^{w}-\xi_{r}^{w}}{\sigma^{w}}\right)\right\}^{c_{s i}}
\end{aligned}
$$

\section{Data}

The sample of unemployment spells and re-employment wages is derived from the National Longitudinal Survey of Youth 1979 (NLSY79). Here, we 
constructed panel data containing individual weekly job histories up until the time of the 2002 survey.

All demographic variables are updated on a yearly basis and the value at the beginning of the year in which a job loss occurred is assigned to that particular job loss episode.

Using data on state UI rules contained in the Department of Labor's semiannual publication Significant Provisions of State Unemployment Insurance Laws we compiled state UI policy rules on such parameters as the maximum benefit amount. Based on these policy rules and weekly earnings history, we determined eligibility and calculated the weekly benefit amount (WBA) that individual's qualified for. We also determined whether a state required a waiting period, the maximum duration of regular benefits, and whether the state had extended benefits in a year. Moreover, state level variables based on administrative data were constructed for UI initial claim denial rates, on-going-claim denial rates, state average real WBA. Only unemployment spells where an individual did not return to the previous employer are included in the analysis. Selected summary statistics are reported in Table 1. A sample consists of a total of 13,387 spells of unemployment associated with 5732 individuals.

\section{Results}

The impact of UI receipt and unemployment durations on the re-employment wage are identified by the state's average denial rates and by spouse's past use of UI and by the time-varying nature of the state's monthly unemployment rate over an unemployment spell. Table 2 shows the coefficient estimates of for a model with a three mass-point distribution. Here we discuss only coefficient estimates associated 
with variables pertaining to UI system, in particular, WBA and duration of benefits, on re-employment wages. These are reported in column (3) of Table 2.

Here we see that the impact of WBA for UI recipients on the re-employment wage as measured by the coefficient of WBA x UI is positive and statistically significant. This positive impact, however, is for unemployment spells equal to 1 week. Thus, initially, a $\$ 100$ increase in weekly benefits increases the re-employment wage by nearly 7 percent. The negative and statistically significant coefficient on the interaction variable ui $\mathrm{x}$ spell $\mathrm{x}$ wba implies, however, that the impact dissipates with the length of the unemployment spell. Specifically, the effect of a $\$ 100$ increase is zero after approximately 34 weeks of unemployment which is consistent with search models that predict that the reservation wage decreases smoothly to that of a non-recipient at the time of benefit exhaustion.

The coefficient associated with the duration of regular UI benefits is positive and statistically significant and suggests that increasing the duration of UI benefits by 1 week increases re-employment wages by approximately one percent.

\section{Conclusion}

In this paper we develop a random-effects panel data model, which jointly models probability of UI receipt, the unemployment duration and re-employment wage in each job loss episode of an individual, to estimate the impact of UI policy characteristics such as the weekly benefit level and regular benefit durations on an individual's reemployment wage following a spell of unemployment. The model estimates show some evidence of the positive effect of WBA on re-employment wages but only for those with short unemployment durations. Empirical support was 
also found for the notion that an increase in the regular duration of benefits increases re-employment wages which is also predicted by theoretical models of job search.

\section{References:}

Addison, John T and McKinley L. Blackburn (2000) "The Effects of Unemployment Insurance on Postunemployment Earnings,” Labour Economics, 7, 21-53

Card, D. and Levine, P. (2000) "Extended Benefits and the Duration of UI Spells: Evidence from the New Jersey Extended Benefit Program,” Journal of Public economics, 78, 107-138.

Devine, T.J., and Kiefer, N.M. (1991), Empirical Labor Economics: The Search Approach. Oxford: Oxford University Press.

Fallick, B.C. (1991) "Unemployment Insurance and the Rate of Re-employment of Displaced Workers,” Review of Economics and Statistics, 73, 228-235.

Ham, J., and Rea, S. A. (1987) "Unemployment Insurance and Male Unemployment Duration in Canada” Journal of Labor Economics, 5(3), 325-353.

Meyer, B. D. (1990), "Unemployment Insurance and Unemployment Spells.”

Econometrica, 58, 757-782. 
Table 1

Summary Statistics

$(n=13,387)$

\begin{tabular}{lrr} 
Variables & \multicolumn{1}{c}{$\begin{array}{r}\text { Standard } \\
\text { Deviation }\end{array}$} \\
\hline \hline WBA & $\$ 142.83$ & $\$ 87.97$ \\
Ul receipt (UI) & 0.22 & \\
Claim Denial Rate & 0.10 & \\
Maximum Duration of Regular Benefits & 20.22 & 8.77 \\
State has Waiting Week & 0.82 & \\
State had Extended Benefits in Year of Job Loss (EB) & 0.67 & \\
Denial Rate - On going claims & 0.14 & \\
State Average Real WBA in Year of Job Loss & $\$ 215.47$ & $\$ 35.41$ \\
State Unemployment rate & 7.17 & 2.29 \\
High Quarter Earnings & $\$ 4,449$ & $\$ 2,291$ \\
Base Period Earnings & $\$ 12,576$ & $\$ 4,617$ \\
\hline \hline
\end{tabular}

Source: NLSY79. See text for details 
Table 2: Model Estimates with Three Mass Point Unobserved Heterogeneity $(n=13,387)$

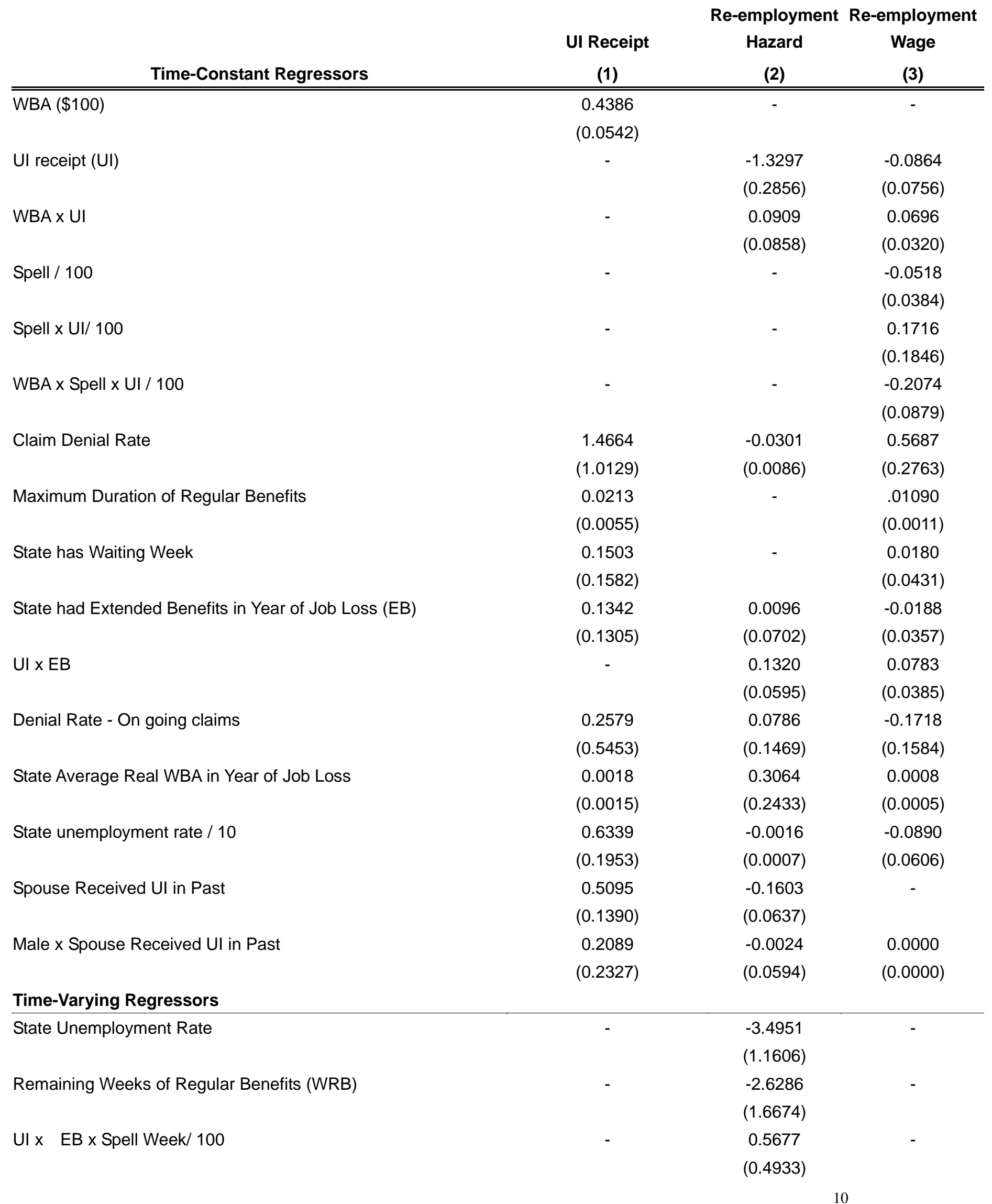




\begin{tabular}{|c|c|c|}
\hline & -0.0030 & - \\
\hline & $(0.0039)$ & \\
\hline \multirow[t]{2}{*}{ - } & 119.0140 & - \\
\hline & (28.9396) & \\
\hline \multirow[t]{2}{*}{ - } & -90.7105 & - \\
\hline & $(35.4943)$ & \\
\hline \multirow[t]{2}{*}{ - } & 1.7171 & - \\
\hline & 1.2082 & \\
\hline \multirow[t]{2}{*}{-} & 11.6694 & - \\
\hline & (2.7730) & \\
\hline \multirow[t]{2}{*}{ - } & -2.6774 & - \\
\hline & $(0.7582)$ & \\
\hline \multirow[t]{2}{*}{-} & 0.1707 & - \\
\hline & $(0.0571)$ & \\
\hline \multirow[t]{2}{*}{-} & -1.0538 & - \\
\hline & $(0.9531)$ & \\
\hline \multirow[t]{2}{*}{-} & 0.3204 & - \\
\hline & $(0.2779)$ & \\
\hline \multirow[t]{2}{*}{-} & -0.0022 & - \\
\hline & $(0.0022)$ & \\
\hline \multirow[t]{2}{*}{-} & -0.0022 & - \\
\hline & $(0.0021)$ & \\
\hline
\end{tabular}

UI x EB x Spell Week Cubed/100000

UI x WRB x Spell Week/100

$-90.7105$

UI x WRB x Spell Week Squared/10000

1.7171

UI x WRB x Spell Week Cubed/100000

11.6694

UI x Spell Week/100

$-2.6774$

UI x Spell Week Squared/10000

UI x Spell Week Cubed/100000

UI x WBA x Spell Week/100

UI x WBA x Spell Week Squared/10000

UI x WBA x Spell Week Cubed/100000

(0.0021)

Log Likelihood $=-119,225.64$

Notes: Standard errors are in parentheses. Data from the NLSY79, see text for details. Estimations also include controls for gender, race, marital status, age, age squared, number of children, children 0-2, live with parents, family size, years of schooling, AFQT percentile, health limitations, interactions of gender with race, age, marital status, and living with parents, tenure, tenure squared, union status, lost job due to plant closing, industry, occupation, state of residence, resides in SMSA, month of job loss, year of job loss, dummies for high quarter earnings indicating whether high quarter earnings were between 0-1, 1-2, 2-3, 3-4, 4-5, 5-6, 6-7, 7-8, 8-9, and 9-10 thousand dollars and dummies for base period earnings indicating whether base period earnings were between 0-2, 2-4, 4-6, 6-8, 8-10, 10-12, 12-14, 14-16, 16-18, 18-20, 20-25 and 25-30 thousand dollars. 